\title{
Innovative and information technologies in the educational process at the pedagogical university
}

\author{
Alfinur Galiakberova ${ }^{1 *}$ \\ ${ }^{1}$ History and Methods of its Teaching Department Naberezhnye Chelny State Pedagogical University \\ Naberezhnye Chelny, Russia
}

\begin{abstract}
Education is one of the most important human values in the modern world. It has become the key thing that helps people determine their life orientations, enrich their culture, promote their professional growth, and achieve their social status. It concerns all the stages of the educational system especially higher pedagogical education. The traditional approaches used in the educational process are changing under the influence of intensive developing the computer technologies and improving the educational technologies. The application of interactive, information and communication technologies to the modern education system is becoming wider and wider. The article discusses the key issues of the innovation policy in the modern education and the practical experience gained when using the innovative and information technologies at the Naberezhnye Chelny State Pedagogical University (NSPU).
\end{abstract}

\section{Introduction}

The innovative processes involve both developing and applying the new teaching methods and significant changing in the teachers and students' way of thinking, and striving to the broader use of gained knowledge in the learning process [1], [2], [3].

Innovative pedagogy is the ability to use the new methods in practice and significantly improve the process of learning and teaching. But without developing the scientific activity it is impossible to apply the new methods, since they have to be developed and tested [4], $[5]$.

There is a group of factors that directly affect the development of innovative processes. They include:

- Culture of communication between organizational structures and teaching staff of educational institutions [6], [7], [8].

- Management openness to applying the new technologies in education [9, [10], [11].

- Communication processes both within and outside the system [12], [13], [14].

- Bureaucratic barriers in the education management system [15], [16].

— Preparatory work with the different groups of academic disciplines [17], [18].

\footnotetext{
* Corresponding author: ngpi@tatngpi.ru
} 
Summarizing the views of many authors, N.I. Kargin, V.G. Svinarenko, O.A. Kozyreva [19] distinguish the subject, the purpose, and the objectives of innovative pedagogy.

The subject of innovative pedagogy is modeling and using the pedagogical innovations that improve professional and pedagogical activity.

The purpose of innovative pedagogy is identifying and meeting the challenges with optimal and deterministic resources that represent the field of innovative products and objects of the modern pedagogical science, culture and art (skill).

The objectives of innovative pedagogy are:

- to determine the current pedagogical challenges in the system of continuing education;

- to model the new pedagogical tools in the verification structure of the quality of pedagogical activity and communication:

- to test the new pedagogical tools in the verification structure of the quality of pedagogical activity and communication;

- to use the new pedagogical tools and innovations in teaching practice;

- to apply the acquired experience in defining and responding to the current pedagogical challenges to the model of creating and using innovations.

T.A. Kolesnikova, Z.U. Kolokolnikova, and O.B Lobanova [20] believe that innovative technologies used in subject teaching can be divided into two groups.

1. General technologies:

- information and communication technologies (ICT)

- information and analytical support of training and education quality management;

- didactic technologies;

- health-saving technologies.

2. Technologies that are based on the learner-centered approach:

- personality-oriented technologies;

- psychological and pedagogical support for the innovative technologies;

- monitoring the intellectual development;

- educational programs;

- technology of advanced training.

\section{Materials and methods}

The methodology of modern innovative pedagogy should be based on such key principles as scientific character, consistency, integrity, objectivity, reliability, social orientation, and verification.

However, the principle of integrity of pedagogical theory and pedagogical practice is the most important one.

Despite the importance of theoretical approaches, it is necessary to keep in mind that current pedagogical technologies are closely connected with information and communication technologies. The innovative activity should be considered to be one of the key things of organizing the educational process in a pedagogical university. In addition, it is the most important factor of effective training the future teachers. The analysis of pedagogical activity in Naberezhnye Chelny State Pedagogical University makes it possible to identify the following types of innovations in educational practice:

- applying a digital simulator of pedagogical activity;

- using electronic library resources;

- using the advanced equipment in the complex research laboratory;

- applying the modern technologies to professional health saving;

- developing the important competencies, such as the further education qualification;

- applying the distance education technologies. 


\section{Results}

Innovative education in NSPU is integration of modern information technologies, teaching methods and interactive, advanced equipment. The equipment is used to help with transforming general information into personal knowledge and skills of students.

\subsection{Educational activity simulator}

This is a project that is successfully implemented within the joint activity agreement between the NSPU Laboratory of Pedagogical Innovations and the University of Reims, Champagne-Ardennes, France.

The developed simulator allows combining theory and practice in the sphere of training a primary school teacher of Mathematics. It is a virtual simulation of the methodical analysis of a lesson. Guiding the "tutor's" actions, a student goes through all the stages of the lesson analysis discussing them with the virtual teacher. A student chooses a sequence of questions and the right options. Based on the teacher's comments, the student guides the process of viewing the video fragments of a lesson, which demonstrate the joint activities of a teacher and students. We have developed the original model of a Math lesson using activity-based educational approaches.

The next stage is developing a simulator for other subject areas (History, Geography, Literary Reading, etc.). The group of university researchers studies the professional activity of a teacher, taking into account Russia's educational standards and activity-based technologies aimed at achieving intersubject and metasubject outcomes.

The results obtained in the course of testing can be used by teachers of higher education, representatives of Institutes of Further Education to develop methodological skills of future teachers.

\subsection{Electronic library resources}

They play a significant role in modern education, as they are the main source of materials for electronic textbooks and allow students and teachers to have high-quality and effective access to any information.

The students, attending the university library, register in the automated information and library system "Ruslan" using electronic campus cards. In addition, the system makes the automated book delivery of educational literature to students. At present, more than $96 \%$ of students and all the university staff are registered in the electronic library systems.

Naberezhnye Chelny State Pedagogical University has also reached an agreement with the IPR BOOKS and Urait electronic library systems to have access to their electronic resources.

In 2018 the university received a certificate that states that the university is a participant of the network project SCIENTIFIC and EDUCATIONAL PLATFORM "Open Pedagogical Education" within the electronic library system IPR BOOKS.

More than 300 publications of NSPU teachers were displayed on the network scientific and educational platform "Open Pedagogical Education".

The University has been successfully cooperating with the leading Russian electronic library system Urait since 2019. The Urait platform is actively used by the students and teachers for learning and training.

According to the Urait Platform.Statistics, NSPU is ranked 35th among 763 universities in Russia and the former Soviet Union in the Ranking of Digital Activity. 


\subsection{Complex Research Laboratory}

It was founded in 2019. Now the laboratory makes a significant contribution to the process of giving practice-oriented training, providing the educational process with special equipment, and establishing metasubject and intersubject relations.

\subsubsection{Techniques of computer psychological and psychomotor testing}

At the Department of Pedagogy, the students are taught these techniques within Psychopedagogical module when studying such subjects as "Theory and Technology of Education", "Theory and Technology of Teaching", "Psychological and Pedagogical Workshop", "Modern Russian and Foreign Didactic and Educational Systems of Preprimary, Primary and General Education". In the course of training they are taught to use the "Psychophysiologist" testing device with psychomotor tests and the "Cicero" computer program.

\subsubsection{Sign language, typhlotechnical and speech therapy equipment}

The laboratory has "Logomer" software and diagnostic system, the "Dialog", "Globus", "Monolog", "Videouvelichitel" devices, the "Sonet" radio class, portable computer with Braille, speech synthesizer, and interactive panel. The equipment is used by the students at the practical classes that take place in specially equipped rooms. It enlarges students' knowledge in the field of inclusive psychological and pedagogical support. Also, the equipment helps to develop the communication skills of students with visual, hearing, and musculoskeletal disorders.

\subsubsection{Research activity}

The students, who have shown a scientific interest in the field of individual and differential education of children, including those with special educational needs, join the students' scientific society.

\subsubsection{Technologies in the field of literature and linguistics}

Within the scientific activity the students develop and apply technologies that teach primary school children to write, read, and develop imaginative speech using the Movie Marker program on the SMART interactive display. The program helps to practice proper breathing and sounds reproducing in the "biofeedback" mode.

The students of the Philological Department together with the teachers of the Chair of Russian and Tatar Philology study of the properties of the voice, its strength, tempo, timbre, and the intonation patterns of the Russian language within the "Russian Language and Speech Culture", "Expressive Reading", and "Modern Russian Language" courses. The speech therapy equipment with the BOS LOGO technology of biological feedback and the "Delfa" simulator are used to do this.

\subsubsection{Technologies in the field of speech therapy}

Within the "Speech Therapy", "Forms of Speech Therapy", and "Speech Workshop" practical courses the students majoring in "Correctional Pedagogy in Primary Education" analyze the structure of speech defect, the model and the quality of the speech training, 
diagnose the disorders of oral and written speech using a computer program developed by the Studio "Viel". They have classes at a specially designed therapist's office in a helpful learning environment. At their classes they fill in speech electronic files, study the speech therapy profiles and make preliminary speech therapy diagnoses. Then taking into account the speech, locomotion, or mental disorders the students plan some remedial work and select the necessary equipment to improve breath, articulation, voice, speech, and locomotion (the "Delfa" speech therapy and training machine, the "Globus", "Monolog" devices, and the LOGO, NEIROKURS, Timokka didactic systems). Using didactic and interactive games of the "Lagomar" device, the students develop the speech correction skills.

To optimize and improve speech therapists' performance when treating dysgraphia in primary school children the students study computer-didactic system "Sea of Literature". Working in pairs, they practice the techniques for diagnosing and correcting the written speech disorders.

\subsubsection{Health saving}

The issues of teachers' health are studied at the University. The "Psychophysiologist" testing device and the module of psychomotor tests were used to study the personality characteristics of young teachers working at Naberezhnye Chelny-based secondary school No. 42. The school, where $30 \%$ of teachers are the NSPU graduates, is the training field of the University. The findings of the study showed that there was some tension of regulatory mechanisms and signs of socio-psychological and psychological-pedagogical disadaptation in teachers. That indicated that their professional health weakened and adaptation to the educational process went wrong. Based on the data obtained, the program of support for young teachers was developed. It was aimed at resisting the stressful educational factors alongside with achieving the necessary psychophysiological status.

\subsubsection{Students' health}

Health and safety of university students and their healthy lifestyle are the most important activity of the complex research laboratory. The state of physical health and functional potential of the students are examined in the first year. The "Spirolan" spirograph and the "Psychophysiologist" device measure the main anthropometric, physiometric and psychological indicators, calculate the physical condition index, analyze the functional potential, and assess the state of physical and psychological health. The results are recorded in specially developed students' health cards and taken into account when arranging the students into groups at physical education classes. Special attention is paid to the health of students who are included in special medical groups or engaged in sports activities. The individual recommendations on disease prevention, lifestyle correction, and risk factors are developed for them.

The scientific group of the leading teachers of the Physical Education and Sports Department and senior students involved in the "Territory of Health" project make dynamic observations of the health of students with different levels of motor activity using advanced equipment.

The students majored in "Applied Informatics" have developed software and a database of health indicators of the University students. It greatly helps gather and find the information about changes in the physical and mental health of every student. 


\subsubsection{Professional consulting and professional orientation}

When having practical classes in "Personality Psychology and Professional Selfdetermination", "Social Adaptation and the Basics of Social and Legal Knowledge", the students study the latest computer professional testing technologies such as "Professional Navigator", "Professional Orientation", "Professional Career", "Personality and Professions". Application of these technologies help the university students develop their skills in holding professional consultations and career-oriented interactive games with urban and rural schoolchildren using a specially developed methodological manual "Lap book "Professions". Under the guidance of a psychologist-professional expert, the students develop methods of using professional simulators and participate in building the individual career paths.

\subsection{Creative technologies}

The undergraduates improve the skills of applying the research methods for developing creative thinking, design thinking, and emotional intelligence at the Department of Arts and Innovative Design.

In the course of training the college students, the undergraduates use the BOSNEIROKURS System to monitor neuropsychological and physiological characteristics and learning skills when studying such subjects as "Subject Design", "Innovations in Design", "Digital Technologies for Designing and Producing Design Objects", "Urban Environment Design".

\subsection{Additional competencies of students}

The university has excellent conditions for acquiring additional professionally significant competencies, developing the new methodological systems of teaching and educating based on the strategic policies of Russian and foreign education.

One more innovative educational project is that the University offers its students the "Teacher of Further Education" qualification given in the final year. In the course of taking their bachelor degrees, the students are offered a wide range of further education including patriotic education, scientific design, volunteer, creative and sports activities.

Each training course lasts for 1 year and covers 250 academic hours including theoretical training, practical experience, and work-based training. Upon completing the course of study, the students demonstrate the practical outcomes and acquired competencies. The number of areas that a student can choose during a year is not limited, but a graduate has to study at least four of them to get the "Teacher of Further Education" qualification.

Thus, the students who have successfully completed all the necessary courses become competent specialists who are ready to work as teachers, including the areas of further education. The acquired qualifications give the university graduates greater opportunities.

\section{Conclusion}

The socio-psychological characteristics of students and young teachers that have been studied allow us to model the new career paths, improve professional health and develop some innovative technologies to better organize the educational process in a pedagogical university. Applying the psychophysiological methods of biofeedback helps reach a higher level of studying an individual's professional health. The University has joined the team of the "Circular Economy" Scientific and Educational Center that is the world-class center in 
the Republic of Tatarstan. The cooperation with the Center involves participating in the "Development of Scientific and Scientific-industrial Cooperation" Federal project within the "Science" National project.

The above-mentioned innovative and information technologies applied to the educational environment have made it possible to develop an effective electronic educational system in the Naberezhnye Chelny State Pedagogical University. Pedagogical education should encourage innovation, and widely use the latest professional and information technologies at the present stage of its development.

Informatization of the major activities of the University leads to the conclusion that it is urgent to combine information systems and the experience of Russia's pedagogical universities.

This will undoubtedly encourage both the greater integrity and integration of higher pedagogical education in this country and the development of new innovative forms of university activities based on the principles of the activity-based approach and learneroriented technology.

\section{References}

1. V. I. Zagvyazinsky, Innovative processes in education and pedagogical science. Innovative processes in education: Collection of scientific works, Tyumen, Tyumen State University, 8 (1990).

2. Yu. S. Tyunnikov, Analysis of innovative activities of general education institutions: scenario, approach Standards and monitoring in education, 5 (2004).

3. V. S. Lazarev, The concept of the pedagogical and innovative system of the school, Village School, 1 (2003).

4. N. G. Yelensky, Innovative pedagogical activity. Elementary school, 7, 12-16 (2007).

5. N. G. Yelensky, Innovative and experimental activity, Education and upbringing, 6, 31-34 (2007).

6. L. P. Pavlova, Innovative teaching technologies as a factor in creating a single educational standard. Innovative educational technologies, 1(13), 12-16 (2008).

7. I. P. Podlasiy, Pedagogy: New Deal, Moscow, Book 1, 210-212 (2000).

8. L. G. Titarenko, Innovative component in higher education, Vysheyshaya school, 6, 14 (2007).

9. D. R. Garrison, N. Vaughan, Blended Learning in Higher Education: Framework, Principles, and Guidelines. San Fransisco: Jossey-Bass, 246 (2008).

10. E. V. Krasnoshchekov, Innovative educational technologies in a modern school in Germany. The author's abstract on competition of a scientific degree of the candidate of pedagogical sciences. Taganrog (2000).

11. E. Allen, J. Seaman, R. Garrett. Blending In. The Extent and Promise of Blended Education in the United States. Sloan-C (2007).

12. S. V. Konovalov, O. A. Kozyreva. Teacher modeling constructs of contemporary education, Tomsk state pedagogical university bulletin, 1, 58-63 (2017).

13. P. R. Atutov, Technology and modern education, Pedagogy, 2 (1996).

14. H. Singh, Building Effective Blended Learning Programs, Issue of Educational Technology, 43(6), 51-54 (2003).

15. I. Tsyrkun, Development of metacognitive concepts of innovation and educational activity. Pedagogical innovations, 1, 37-42 (2004). 
16. N. I. Erofeeva, Project Management in Education, Public Education, 5 (2002).

17. A. S. Belkin, Vital training with a holographic projection method, School technology, 3 (1998).

18. V. I. Reviakina, Problems of scientific activity of the teacher of higher school. Information and education: the boundaries of communications, 3(11), 125-127 (2011).

19. T. A. Kolesnikova, Z. U. Kolokolnikova, O. B Lobanova, Application of innovative technologies in the educational process of a modern school, Scientific Review. Pedagogical sciences, 6-2, 261-269 (2017).

20. N. I. Kargin, V. G. Svinarenko, O. A. Kozyreva, Innovative pedagogy as a product and condition for the development of modern education, Bulletin of the Kemerovo State University. Series: Humanities and Social Sciences, 3, 26-32 (2018). 